\title{
THE CORRELATION OF CD3 IMMUNOHISTOCHEMICAL EXPRESSION WITH INTRATUMORAL TUMOR- INF ILTRATING LYMPHOCYTES (TILS) AND HISTOPATHOLOGICAL GRADING OF ADENOCARCINOMA COLON
}

\author{
Fahmi Irsan Nasution, Betty, Nadjib Dahlan Lubis, Joko S. Lukito, Soekimin \\ irsanfahmi89@gmail.com \\ Department of Anatomical Pathology, Faculty of Medicine, Universitas Sumatera Utara, Medan, Indonesia
}

\begin{abstract}
Background. The most common malignant epithelial tumor originating from the colon is adenocarcinoma, which accounts for $>90 \%$ of all colon carcinomas. Tumor-infiltrating lymphocytes (TILs) have been extensively studied and are associated with prognostic factors for several solid tumors. Research of TILs with CD3 immunohistochemistry staining for adenocarcinoma colon is still rarely done until now.
\end{abstract}

Objective. the correlation of CD3 immunohistochemical expression with the degree of Tumor-Infiltrating Lymphocytes (TILs) intratumoral and histopathological grading of adenocarcinoma colon.

Materials and Methods. Analytical study with a cross-sectional approach using slides and paraffin blocks of adenocarcinoma colon patients with CD3 immunohistochemical staining. Statistical analysis was performed with Chi-Square and Eta. to see the relationship of intratumoral TILs with histopathological grading of adenocarcinoma colon.

Results. It was found in this study that the most were low-grade adenocarcinoma of the colon as many as 28 cases $(87.5 \%)$ and the least was high-grade adenocarcinoma of the colon as many as 7 cases (21.9\%). The degree of intratumoral TILs in this study was found in 32 cases (100\%). In CD3 immunohistochemistry staining, 25 positive results (78.1\%) and negative results in 7 cases (21.9\%), Chi-Square test was carried out on the correlation grading with CD3 display, p-value $=0.201$ ( $>$ >0.05). While the correlation between the degree of TILs with CD3 immunohistochemical expression using the Eta test obtained $p$-value $=0.05(\mathrm{p}>0.05)$.

Conclusion. There is no effect of histopathological grading with CD3 immunohistochemical expression and there is a significant relationship between the number of degrees of intratumoral TILs and CD3 immunohistochemical expression with a strong correlation and a positive direction.

Keywords: Adenocarcinoma colon, TILs, grading, CD3.

\section{Introduction}

The most common malignant epithelial tumor originating from the colon is adenocarcinoma, which accounts for $>90 \%$ of all colon carcinomas.[1] Dietary factors that are closely related to the increase in the number of carcinoma colon are low intake of vegetable fiber and high intake of refined carbohydrates and fats. Colon cancer is thought to be mediated by inhibition of the enzyme cyclooxygenase-2 (COX-2), which is highly expressed in $90 \%$ of colorectal carcinomas and $40 \%$ to $90 \%$ of adenomas and is known to accelerate epithelial proliferation, especially in response to injury. [2,3]

According to GLOBOCAN 2018 data, carcinoma colon ranks 4th most common cancer worldwide after lung, prostate, and stomach in men and 3rd in women after breast and uterus. In 2018, more than 1.8 million new cases were discovered and 881,000 deaths due to carcinoma colon [4] Indonesia ranks 3rd for colorectal cancer, this is due to changes

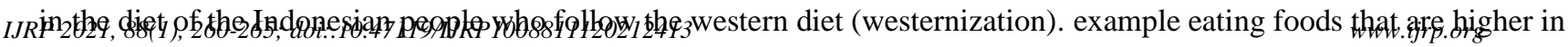


fat and low in fiber. Generally, cases of colon carcinoma are only known when cancer has entered a more advanced stage. This is due to a lack of public knowledge about cancer and only to consult a health care provider if there are symptoms that interfere with activity.[2,4] According to the American Cancer Society, colon carcinoma is the third most common cancer and is the second most common cancer cause of death in the United States. male and female populations in the United States.[4] The risk of colon carcinoma begins to increase at the age of 60-70 years and less than $20 \%$ of cases occur before the age of 50 years. Now the age shift has begun. Many colorectal cancers are found at a younger age, this is due to an unhealthy lifestyle.[1,2,6]

Tumor-Infiltrating Lymphocytes (TILs) are one of the immune cells that play an important role and can be found in primary and metastatic tumors. An increase in both intratumoral and stromal TILs is associated with a better prognosis although several studies have suggested that stromal TILs have a significant effect.[9] TILs are not randomly distributed, but accumulate in an organized manner in dense or small amounts in various parts of the tumor and interact with each other. Studies have shown that these tumor-infiltrating lymphocytes consist not only of CD8+ and CD4+, but also other groups of lymphocytes such as T cells, B cells, NK cells, and NKT cells. Each of these lymphocytes has an important role in the regulation of anti-tumor immunity. CD8+ T cells or known as cytotoxic CD8+ T cells (CTL) function to destroy tumor cells by binding to antigens presented by MHC class I molecules that are expressed on the membranes of all nucleated cells. These CTLs are inactivated by regulatory T cells (Treg), interleukin 10, and other cytokines that prevent autoimmune diseases. CD4+ T cells, also known as helper T cells (Th cells) play a role in mediating the immune response of other white blood cells. These cells help the maturation of B cells into plasma cells and memory B cells and activate CTL and macrophages. The cells become activated when they come into contact with peptide antigens expressed by MHC class II molecules present on antigen-presenting cells (APCs). This type of immune response is classified as type II immunity, which must be distinguished from the type I immunity carried by the CTL. When Th cells are activated, these cells will undergo rapid division and release cytokines that will mediate active immunological reactions. Treg cells expressing FOXP3 are controversial because Treg cells are associated with immunosuppressive and immunostimulatory activities.[10]

The grading of colorectal adenocarcinoma is based on gland formation, namely: (1). Low grade, ie colorectal adenocarcinoma well-differentiated (well-differentiated) to moderate (moderately differentiated). Colorectal adenocarcinoma is said to be well differentiated if $\geq 50 \%$ glandular formation is found and (2). High grade, namely poorly differentiated colorectal adenocarcinoma (poorly differentiated). Colorectal adenocarcinoma is said to be poorly differentiated if $\geq 50 \%$ glandular formation is present.[7,11]

A cluster of differentiation 3 (CD3) is a multimeric protein complex, known as the T3 complex, and consists of four distinct polypeptide chains; epsilon $(\varepsilon)$, gamma $(\gamma)$, delta $(\delta)$, and zeta $(\zeta)$, which assemble and function as three pairs of dimers ( $\varepsilon \gamma$, and ). Each of these chains contains immunoreceptor tyrosine activation motifs (ITAMS) required for the initiation of the signaling cascade, as these chains recruit protein tyrosine kinases, signaling intermediates, and adapter molecules. CD3 is a member of the immunoglobulin superfamily and acts as a signal transduction mediator.[12]

\section{Material and Method}

We examined 32 cases of adenocarcinoma colon histopathology slides at the Anatomic Pathology Laboratory, North Sumatra University and Anatomic Pathology Unit H. Adam Malik Hospital using an analytical study design with a cross-sectional approach to analyze the corellation CD3 immunohistochemical expression with intratumoral TumorInfiltrating Lymphocytes (TILs) and histopathological grading adenocarcinoma colon with CD3 immunohistochemical staining. 
Histopathological specimens stained with CD3 immunohistochemical staining after fixation with $96 \%$ ethanol and dry fixation were reviewed retrospectively by the authors. Histopathological slides were examined for the presence or absence of stained CD3 immunohistochemical expression on the intratumoral Tumor-Infiltrating Lymphocytes (TILs) in the cytoplasmic and membrane with viewed on 5 HPF 400x enlargement using a CX21 microscope.

\section{Results}

The research sample was a histopathological slide which was diagnosed as adenocarcinoma of the colon at the Laboratory of Anatomic Pathology, Faculty of Medicine, Universitas Sumatera Utara, and the Anatomic Pathology Unit of H. Adam Malik Hospital. The total sample is 32 slides that meet the inclusion criteria. The following are the results of the research obtained.

Table 1. Characteristic distribution of adenocarcinoma colon of study sample.

\begin{tabular}{lll}
\hline No. & Characteristic & Score (\%) \\
\hline 1. & Histopathology grading & \\
& $\bullet \quad$ Low grade & $28(87,5)$ \\
& $\bullet \quad$ High grade & $4(12,5)$ \\
2. & Degree of intratumoral TILs & $32(100 \%)$ \\
3. & CD3 & $25(78,1)$ \\
& $\bullet \quad$ Positive & $7(21,9)$ \\
\hline
\end{tabular}

Based on histopathological grading, the samples of adenocarcinoma colon (Table 4.1) in this study were mostly low-grade adenocarcinoma colon as many as 28 cases $(87.5 \%)$ and a few of high-grade adenocarcinoma colon as many as 7 cases (21.9\%). All of these studies demonstrated a degree of intratumoral TILs. The results of CD3 immunohistochemical staining of adenocarcinoma colon showed more positive results than negative, which showed 25 positive cases $(78.1 \%)$ while 7 cases negative $(21.9 \%)$. (Table 1$)$

Table 2. The correlation of histopathological grading with immunohistochemical expression of CD3 of adenocarcinoma colon

\begin{tabular}{|c|c|c|c|}
\hline \multirow{2}{*}{ Variable } & \multicolumn{3}{|c|}{ CD3 Immunohistochemical } \\
\hline & Negative & Positive & $\mathbf{p}$ \\
\hline \multicolumn{4}{|c|}{ Histopathology grading } \\
\hline Low grade & $5(15,6 \%)$ & $23(71,9 \%)$ & \multirow{2}{*}{0,201} \\
\hline High grade & $2(6,3 \%)$ & $2(6,3 \%)$ & \\
\hline
\end{tabular}

* Chi Square Test

In this study, the results of the Chi-Square correlation test showed that the correlation between colonic adenocarcinoma grading and CD3 immunohistochemistry expression obtained p-value $=0.201(\mathrm{p}>0.05)$ which means $\mathrm{H} 0$ is accepted, where there is no difference in histopathological grading between negative and positive appearances on examination. CD3 immunohistochemistry, so it can be concluded that there is no effect of histopathological grading with CD3 immunohistochemical expression.

Table 3. The correlation test of the degree of intratumoral TILs with immunohistochemical expression of CD3 of colon adenocarcinoma

\begin{tabular}{lcc}
\hline Variable & $\mathbf{N}$ & CD3 Immunohistochemical \\
\cline { 2 - 3 } & $\mathbf{P}$ & $<0,05$
\end{tabular}
*Eta Test

In this study, the correlation between the degree of TILs and CD3 immunohistochemical expression using the Eta test, obtained a value of $p=0.05$ ( $p>0.05)$ which means Ha is accepted, where there is a significant relationship between the number of degrees of intratumoral TILs and CD3 immunohistochemical expression with the correlation is classified as strong and in a positive direction. So it can be concluded that the higher the number of intratumoral TILs, the higher the positivity of $\mathrm{CD} 3$ immunohistochemical expression by $79 \%$. 


\section{A grading sample microscopic the image of adenocarcinoma colon}

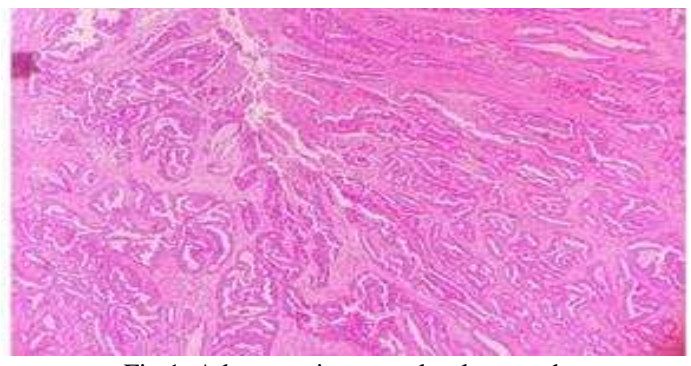

Fig 1. Adenocarcinoma colon low grade

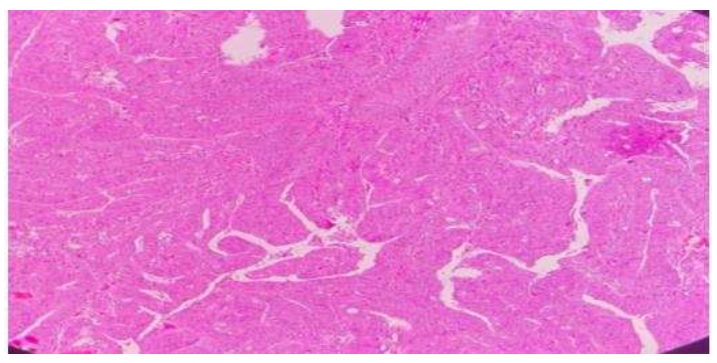

Fig 1. Adenocarcinoma colon high grade

Tampilan Pewarnaan Imunohistokimia CD3

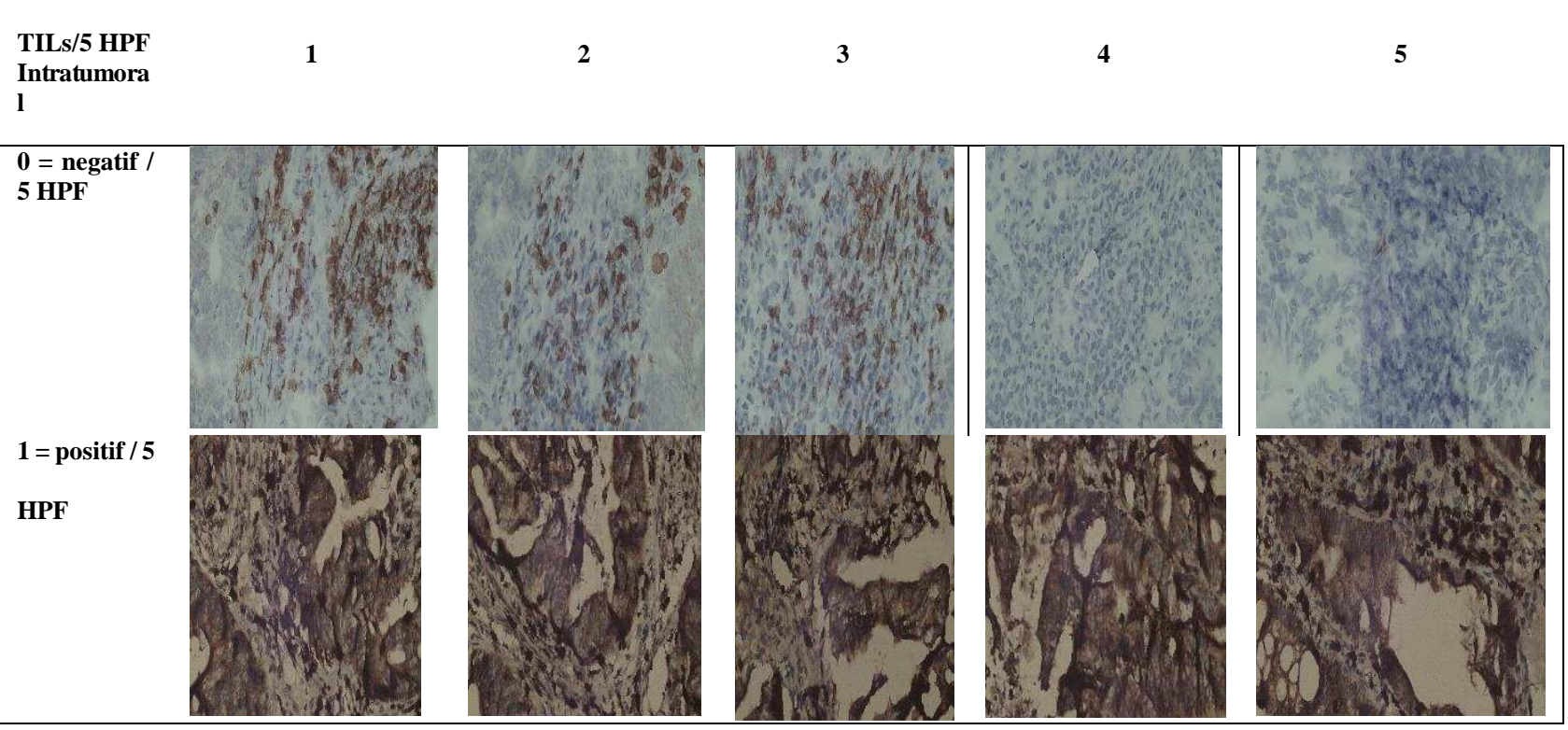

\section{Discussion}

In this study, adenocarcinoma colon patients were recorded in data storage software at the Department of Anatomic Pathology, Faculty of Medicine, Universitas Sumatera Utara and medical records at the Anatomic Pathology Unit at H. Adam Malik Hospital Medan who met the inclusion and exclusion criteria were 32 samples. Histological grading for adenocarcinoma colon is one of the prognostic factors for this malignancy. Based on the classification of the World Health Organization, adenocarcinoma colon is divided into two levels of differentiation based on the structure of the gland, namely low grade and high grade, obtained low grade as many as 28 cases (87.5\%) and high grade as many as 7 cases $(21.9 \%)$. This is different by Pantau, et al., which stated that the most common grading was moderately adenocarcinoma of the colon in 13 cases and the lowest was poorly differentiated adenocarcinoma of the colon in 3 cases. using the latest WHO pathological histology grading assessment in 2019, while the Pantau, et al., used 2017 WHO histological grading assessment.[11]

In this study, tumor lymphocyte cell infiltration (TILs) was observed with hematoxylin \& eosin staining because intratumoral assessment of TILs was easier and these cells showed direct interaction with tumor cells. second-grade adenocarcinoma of the colon. This is similar to the study of Jakubowska, et al., who examined intratumoral TILs on 160 samples with a degree of occurrence or not found in TIL, and in this study, it was found that there were 32 cases of TILs without TILs and 128 cases of TIL. The study of Jakubowska, et al., showed a weak inflammatory response in invasive tumor sites, a low proportion of TILs in tumors associated with increased severity of adenocarcinoma colon.[7] 
In the assessment of CD3 immunohistochemical expression, 25 cases (78.1\%) were positive and 7 cases $(21.9 \%)$. This result is different from the study by Dahlin, et al., who assessed CD3 immunohistochemical expression with three assessments, namely CD3 scores 3-4, 5-6, and 7-12, getting results with a score of 7-12 mostly in cases of adenocarcinoma colon. The results of this study are also similar to those of Yoon et al., which stated that the expression of CD3 immunohistochemistry in adenocarcinoma colon cases was higher with positive results. Immunohistochemistry of CD3 is a marker of T lymphocyte cells that has good sensitivity and specificity. CD3 is also reliable for evaluating tissues with extensive necrosis. This makes CD3 superior among other T lymphocytes detecting antibodies. A negative CD3 immunohistochemical expression indicates the absence of a $\mathrm{T}$ lymphocyte population, this could be due to the absence of $\mathrm{T}$ lymphocytes or due to the proliferation of neoplastic B lymphocytes that suppress the $\mathrm{T}$ lymphocyte population.[13]

The results of the Chi-Square correlation test showed that the correlation between colonic adenocarcinoma grading and CD3 immunohistochemical expression obtained p-value $=0.201(\mathrm{p}>0.05)$, which means that there is no effect of histopathological grading between negative and positive appearances on CD3 immunohistochemistry examination. The results of this study differ from those of Dahlin et al., who stated that there was a relationship between CD3 immunohistochemistry and adenocarcinoma colon grading. T-lymphocytes are found in high-grade, cytotoxic Tlymphocytes are cells that play a role in recognizing and destroying infected or abnormal cells. In addition, cytotoxic $\mathrm{T}$ lymphocyte cells can also suppress the activity of other white blood cells to protect normal tissues. If the number of cytotoxic T-lymphocytes decreases, the number of cytotoxic T-lymphocytes that fight or damage infected cells will also decrease. This is what causes the number of T cells found in high grade.[14]

In this study, the correlation between the degree of TILs and CD3 immunohistochemical expression using the Eta test obtained a value of $\mathrm{p}=0.05(\mathrm{p}>0.05)$, which means that there is a significant relationship between the number of degrees of intratumoral TILs and CD3 immunohistochemical expression with a strong correlation and positive direction. These results are similar to those of Huh JW, et al., which showed a significant difference between the density of TILs and CD3 ( $\mathrm{p}=0.002 ; \mathrm{p}>0.05)$. Another study conducted a calculation of the density of CD3 T lymphocyte cells and compared it with TILs. The results of statistical analysis showed a non-significant difference between CD3 cell density and the degree of differentiation $(p=0.49 ; p>0.05)$ and disease stage $(p=0.29 ; p>0.05)$. This difference is due to the aggregate of CD3-stained T cells including many subsets of $\mathrm{T}$ cells in general (in addition to CD4+ memory $\mathrm{T}$ cells and $\mathrm{CD} 8+\mathrm{T}$ cells). If an immunohistochemical examination of each subset of $\mathrm{T}$ cells is performed, it is possible to find a predominance of pro-tumorgenesis and antitumor inhibitory $\mathrm{T}$ cells in adenocarcinoma colon. The density of intratumoral TILs with CD3 found a relationship in this study. This is possible under the role of T lymphocytes in the cellular immune response. T lymphocytes respond to intracellular antigens in this case are intracellular tumor antigens. There is direct contact with tumor cells that allows this to happen so that many $\mathrm{T}$ lymphocyte cells can be found in the intratumoral area.[12]

\section{Conclusion}

In this study, which was conducted on 32 samples, there was no effect of histopathological grading with CD3 immunohistochemical expression and there was a significant correlation between the number of degrees of intratumoral TILs and CD3 immunohistochemical expression with a strong correlation and a positive direction.

\section{Acknowledgments}

We acknowledgments to all staff and residents of the Department of Pathology Anatomics, UniversitasSumatera Utara / H. Adam Malik Hospital Medan for all your support and guidance. 


\section{REFERENCES}

1. Hamilton RS, Bosman TF, Boffetta P, Iiyas M, Morreau H. Carcinoma of the colon and rectum. 2010. In: Bosman TF, Carneiro F, Hruban HR, Theise DN, eds. WHO Classification of tumours of the digestive system, $4^{\text {th }}$. IARC. Lyon; pp132-46

2. Kumar V, Abbas AK, Fausto N, Aster JC. 2013. Oral Cavity and Gastrointestinal tract. Robbins Basic Pathology. 9th ed. Philladelpia; Elsevier Saunders. pp598-602

3. Pantow PR, Waleleng JB, Sedli PB. 2017. Profil Adenocarcinoma Kolon di RSUP Prof Dr. R. D. Kandou dan Siloam Hospitals Periode Januari 2016-Juni 2017. Jurnal e-Clinic (eCl), Volume 5, Nomor 2; pp. 326-31

4. American Cancer Society. Key Statistics for Colorectal Cancer. [cited 2019 feb 9] Available from: https://www.cancer.org/cancer/colonrectal-cancer/about/key-statistics.html.

5. Benson BA, et al. 2017.Colon cancer, Version 1. J Natl Compr Canc Netw 2017;15(3);pp370-98

6. Komite Penanggulangan Kanker Nasional. Pedoman Nasional Pelayanan Kedok-teran Kanker Kolorektal. Jakarta, 2014

7. Jakubowska K, Kisielewski W, Kańczuga-KL, Koda M, Famulski W. 2017. Stromal and intraepithelial tumor-infiltrating lymphocytes in colorectal carcinoma. Oncol Lett. Dec; 14(6): pp6421-32

8. Perez EA, Ballman KV, Tenner KS, Thompson EA, Badve SS, Bailey H,Baehner FL. 2016. Association of Stromal Tumor-Infiltrating Lymphocytes With Recurrence-Free Survival in the N9831 Adjuvant Trial in Patients With Early-Stage HER2-Positive Breast Cancer. Jama Oncol. Jan 1; 2(1): pp56-64

9. Matsutani S, Shibutani M, Maeda K, Nagahara H, Fukuola T, Iseki Y, et al. Verification of the methodology for evaluating tumor-infiltrating lymphocytes in colorectal cancer. Oncotarget. 2018 Mar 16; 9(20): pp15180-197

10. Lee CT, Huang YC, Hung LY, Chow NH, Su Pei-fang, Ho Chung- Liang et al. Serrated adenocarcinoma morphology in colorectal mucinous adenocarcinoma is associated with improved patient survival. Oncotarget, 2017, Vol. 8, (No. 21), pp35165-75

11. Nagtegaal ID, Arends MJ, Salto-Tellez M. Colorectal adenocarcinoma. In WHO Classification of Tumours: Digestive System Tumours, $5^{\text {th }}$ WHO Classification of Tumours Editorial Board (Ed), International Agency for Research on Cancer. Lyon 2019. pp177-87

12. Huh JW, Lee JH, Kim HR. Prognostic significance of tumor-infiltrating lymphocytes for patients with colorectal cancer. Arch Surg. 2012; 147. pp366-71.

13. Yoon H, Shi Q, Heying E, Muranyi A, Bredno J, Ough F,et al. Intertumoral Heterogeneity of CD3p and CD8p T-Cell Densities in the Microenvironment of DNA Mismatch-Repair-Deficient Colon Cancers: Implications for Prognosis. Published OnlineFirst October 9, 2018. pp1-10

14. Dahlin A, Henriksson M, Guelpen B, Stenling R, Oberg A, Rutegard J, et al. Colorectal cancer prognosis depends on T-cell infiltration and molecular characteristics of the tumor. Modern Pathology. 2011. pp671-682 